\title{
The Impact of Grade Incentives and Gender on Student Performance: An Experiment
}

\author{
Mehreen Amjad Furqan, ${ }^{*}$ Sohnia Salman, ${ }^{* *}$ Sohail Zafar ${ }^{* * *}$
}

\begin{abstract}
This experiment was conducted to determine the impact of grade incentives and gender on student performance at the university level. We perform a two-way analysis of variance on a sample of three groups of students taking a first-year core mathematics course and another three groups taking a fourth-year compulsory accounting course. We find that grade incentives significantly affect student performance for both sampled courses across all six groups. Gender is found to significantly affect the performance of mathematics students, but not of accounting students. The interaction between gender and grade incentives does not have a significant impact on performance in either experiment.
\end{abstract}

Keywords: student performance, grade incentive, gender, experimental research, accounting students, mathematics students.

\section{JEL classification:A22, M20.}

\section{Introduction}

Students' academic performance has been extensively researched over the last eight decades from numerous perspectives. It is affected by cognitive as well as motivational factors (Richardson, Abraham, \& Bond, 2012). Performance-related motivation is divided into intrinsic and extrinsic factors (Griffin, MacKewn, Moser, \& VanVuren, 2013; Matei \& Abrudan, 2011). Of the latter, grades are an important factor affecting student performance (Maksy, 2012a, 2012b). MacDermott (2013) reports that alternative grading policies have a significant impact on student performance: when different methods are employed to improve students' grades, such as dropping the lowest graded assignment, they perform

\footnotetext{
*Senior teaching fellow, Lahore School of Economics.

** Senior teaching fellow, Lahore School of Economics.

${ }^{* * *}$ Professor and dean of business administration, Lahore School of Economics.

We would like to thank Dr. Rabab Mudakar for her constant guidance and support in helping us conduct this study.
} 
better on their final exam for that course. Grant and Green (2013), however, find that grade incentives have no significant impact on performance.

The literature exploring the effect of gender on academic performance, while extensive, is not necessarily conclusive. Some studies report that gender has a significant effect on performance while others find it is not a significant factor. Many studies have looked at the impact of gender on performance in conjunction with other factors, such as personality type. Russo and Kaynama (2012) report that women students with a "judging type" personality perform better. Arthur and Everaert (2012) find that gender has a significant impact on examination performance: based on a sample of accounting students, they note that women performed better overall in the examination, but that gender played a more significant role in subjective questions than multiple-choice questions. On the other hand, Picou (2011) and Borg and Stranahan (2002) find no significant impact for gender on student performance.

Adopting an experimental approach, this study runs univariate tests to determine the impact of grade incentives and gender differences on student performance at the university level. We address the following research questions:

Do grade incentives influence student performance?

Do gender differences influence student performance?

Does the interaction between grade incentives and gender differences affect student performance?

\section{Theoretical Background}

Earlier discussions have focused on how students perform in different subjects. Harbeson (1943) observes that better textbooks and course material improve student performance in any subject. How students participate in the learning process is also discussed as an important aspect of learning and performance. Joseph (1965) examines role-play by students of economics and argues that exercises in which they were asked to act out real-life scenarios enabled a better understanding of the concepts being taught. Doney and Neumann (1965) find that neither teaching methodology nor the weekly frequency of classes affect student performance on accounting courses.

Recent studies have focused on a number of new aspects that might affect student performance. An important factor leading to better 
performance is computer-based problem solving, especially for accounting students (King \&Mo,2013). Hatcher, Henson, and LaRosa (2013) discuss grade point average (GPA) as an intervening factor in the relationship between mode of teaching and performance, where the mode of teaching ceases to be a significant factor while GPA becomes more important.

Motivational factors remain the most widely discussed topic in the literature. Chung's (1968) model predicts student performance based on ability, needs, incentives, and expectations. Grades are an important motivational factor in this context. Carpenter and Strawser (1971) have carried out an experimental study of how grading systems affect student performance. Drawing on a sample of accounting students, they find that a proper grading system improved performance compared to one in which students were told merely whether they had performed satisfactorily. Artés and Rahona (2013) observe that questions assigned as graded problems in an examination increased the performance of a sample of Spanish students compared to questions from an ungraded problem set.

Dobrow, Smith, and Posner (2011) identify a "grading paradox" where by grades are supposed to increase students' interest in a class, but can also do the opposite. Giving students more choice in the classroom increases their interest in that particular subject. Aloysius (2013) builds on this idea and finds that student empowerment is an important factor affecting performance: students who feel they have more choice in what they study are likely to perform better.

The findings on student performance and gender are mixed. Very few studies have looked at the impact of gender alone; most focus on its effect in interaction with other factors. Buckless, Lipe, and Ravenscroft (1991) conclude that gender has a significant impact on performance with women performing better than men on accounting courses. This result also holds when student gender and instructor gender interact, but the effect of gender on performance is reduced if students' previous grades are considered a covariate.

Tan and Laswad (2008) find that gender has a significant impact on students' performance through its effect on their meta-cognitive knowledge. Huh, Jin, Lee, and Yoo (2009) test the effect of several student characteristics on academic performance and observe that gender affects performance more significantly for a sample of offline accounting students than for online accounting students. Marks (2008) studies the impact of 
gender on performance for different socioeconomic groups of students, but does not find that gender has any significant impact in this context.

\section{Framework and Research Hypotheses}

The purpose of this study is to test whether grade incentives and gender affect student performance independently as well as when interacting with each other. The conceptual framework is given in Figure 1.

Figure 1: Model testing student performance

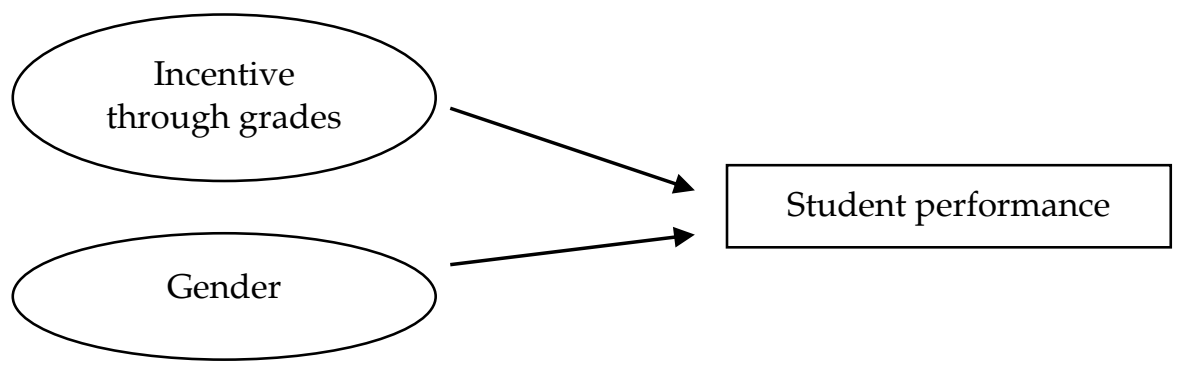

We test the following hypotheses:

Hypothesis $1\left(\mathrm{H}_{0}\right)$ : There is no significant difference in the means of performance across all levels of grade incentives offered to students.

Hypothesis $1\left(\mathrm{H}_{1}\right)$ : There is a significant difference in the means of performance across all levels of grade incentives offered to students.

Hypothesis 2( $\left.\mathrm{H}_{0}\right)$ : There is no significant difference in the means of performance across gender.

Hypothesis 2( $\left.\mathrm{H}_{1}\right)$ : There is a significant difference in the means of performance across gender.

Hypothesis $3\left(\mathrm{H}_{0}\right)$ : There is no significant interaction effect in the means of performance across three levels of grade incentives and both genders.

Hypothesis $3\left(\mathrm{H}_{1}\right)$ : There is a significant interaction effect in the means of performance across three levels of grade incentives and both genders.

\section{Methodology}

This section describes the sample and methodology used, and the variables employed. 


\subsection{Sample}

The study's sample comprised 247university students studying toward a BBA degree. Of these, 120 were studying a first-year core mathematics course and 127 were studying a fourth-year cost accounting course at the same university. The sample included 53 percent men and 47 percent women, and their average age was 21 years.

\subsection{Procedure}

We have employed an experimental factor design (Table 1) to test the relationship between (i) performance and grade incentives, (ii) performance and gender, and (iii) performance and the interaction between grade incentives and gender. The two subsamples (of first-year and fourthyear students divided across six sections) were tested separately. As a laboratory experiment, the study was conducted during class over the same semester. The first-year students were given the same mathematics test and the fourth-year students were given the same accounting test. Both tests had been announced a week before, giving all six sections equal time to prepare.

In both cases, the mathematics and accounting courses represent a separate experiment. Students on each course were divided into two experiment groups and one control group. The first experiment group was given a 5 percent incentive, i.e., they were told the test was worth 5 percent of their course grade. The second experiment group was given a 10 percent grade incentive and the third group (control group) was told that the test was merely for practice and would not be marked.

Table 1: Experimental design

\begin{tabular}{lcc}
\hline & \multicolumn{2}{c}{ Performance observation } \\
\cline { 2 - 3 } Grade incentive & Male & Female \\
\hline $5 \%$ & Y11 & Y12 \\
$10 \%$ & Y21 & Y22 \\
None(control group) & Y31 & Y32 \\
\hline
\end{tabular}

Observations were recorded only after the treatments had been applied. Overall, 96 students were given the 10 percent grade incentive (45 for mathematics and 51 for accounting), 81were given the 5 percent grade incentive (35 for mathematics and 46 for accounting), and 70were assigned the no-incentive condition (40 for mathematics and 30 for accounting). 
We minimized the order-effects bias by changing the order of the experiment groups and control groups for both courses. Thus, in the case of the mathematics course, the no-incentive test took place first, followed by the 5 percent and 10 percent grade incentive tests. In the case of the accounting course, the 5 percent and 10 percent grade incentive tests took place first, followed by the no-incentive test. At the end of the week, once all the tests had been completed, the students were told about the experiment and their grades were included in the study with their consent.

\subsection{Variables}

We have employed three independent variables: grade incentive, gender, and their interaction. In the first case, two levels of grade incentive were offered. Students in the first and second sections were told they could easily improve their performance by sitting a test that would count toward 5 and 10 percent, respectively, of their overall grade. They were also told that the test would include basic questions. The third section or control group was told that sitting the test would not add anything to their grade.

The second independent variable was gender. The sample comprised both men and women, and the purpose was to test for significant differences, if any, in their academic performance. The interaction term was used to determine if grading incentives had a more significant impact on men or women, that is, whether women performed better than men when given a grading incentive (in the two experiment groups) relative to none.

We have hypothesized that academic performance, the dependent variable, is affected significantly by the different levels of incentive given to students. In testing this hypothesis, we have used the marks they obtained as a measure of their performance. According to the second hypothesis, gender is expected to play a significant role in affecting performance and is, therefore, included in the experiment as an independent variable.

\section{Analysis and Results}

A two-way ANOVA was run to test the relationship between the dependent variable (student performance) and independent variables (the different levels of grade incentive and gender). This was done separately for the mathematics and accounting class samples because both courses constitute two different experiments. 


\section{Experiment}

\subsection{Results for Mathematics Students}

Table 2 gives the descriptive statistics (mean performance scores) for the first experiment. Levene's test statistic for the equality of error variances is found to be insignificant, which satisfies our basic assumption about the model being employed. As Table 3 shows, the different levels of grade incentive $(\mathrm{F}=9.923, \mathrm{p}=0.000)$ have a significant impact on student performance. Students tended to perform better when given a higher incentive level. This finding supports the first hypothesis $\left(\mathrm{H}_{1}\right)$ proposing that there are significant differences in the means of performance across different levels of grade incentive.

Table 2: Mean performance scores for mathematics students

\begin{tabular}{llrrr}
\hline Incentive & \multicolumn{1}{c}{ Gender } & Mean & SD & N \\
\hline None & Male & 9.4091 & 4.23600 & 22 \\
& Female & 7.1944 & 3.86971 & 18 \\
& Total & 8.4125 & 4.17546 & 40 \\
$5 \%$ & Male & 10.4750 & 4.90830 & 20 \\
& Female & 8.6333 & 4.05967 & 15 \\
& Total & 9.6857 & 4.59393 & 35 \\
$10 \%$ & Male & 13.5435 & 3.30947 & 23 \\
& Female & 10.7727 & 3.94826 & 22 \\
& Total & 12.1889 & 3.85724 & 45 \\
Total & Male & 11.2000 & 4.47720 & 65 \\
& Female & 9.0182 & 4.17772 & 55 \\
& Total & 10.2000 & 4.46009 & 120 \\
\hline
\end{tabular}

Source: Authors' calculations.

Post hoc comparisons also support this finding: students given a 10 percent grade incentive performed better (had a higher mean score on the test) than those given a 5 percent incentive or no incentive. This finding is supported by the literature, which argues that increasing the level of grade incentive motivates students, who then tend to perform better. 
Table 3: Two-way ANOVA results for mathematics students

\begin{tabular}{|c|c|c|c|c|c|c|c|c|}
\hline \multicolumn{9}{|c|}{ Dependent variable: performance } \\
\hline Source & $\begin{array}{c}\text { Type III } \\
\text { sum of sq. }\end{array}$ & DF & $\begin{array}{l}\text { Mean } \\
\text { square }\end{array}$ & F & Sig. & $\begin{array}{l}\text { Partial } \\
\text { eta sq. }\end{array}$ & $\begin{array}{l}\text { Noncentr. } \\
\text { parameter }\end{array}$ & $\begin{array}{c}\text { Observed } \\
\text { power a }\end{array}$ \\
\hline $\begin{array}{l}\text { Corrected } \\
\text { model }\end{array}$ & 479.021 b & 5 & 95.804 & 5.784 & 0.000 & 0.202 & 28.921 & 0.992 \\
\hline Intercept & $11,752.307$ & 1 & $11,752.307$ & 709.553 & 0.000 & 0.862 & 709.553 & 1.000 \\
\hline Incentive & 328.724 & 2 & 164.362 & 9.923 & 0.000 & 0.148 & 19.847 & 0.982 \\
\hline Gender & 152.014 & 1 & 152.014 & 9.178 & 0.003 & 0.075 & 9.178 & 0.852 \\
\hline $\begin{array}{l}\text { Incentive } \\
\text { * gender }\end{array}$ & 4.355 & 2 & 2.178 & 0.131 & 0.877 & 0.002 & 0.263 & 0.070 \\
\hline Error & $1,888.179$ & 114 & 16.563 & & & & & \\
\hline Total & $14,852.000$ & 120 & & & & & & \\
\hline $\begin{array}{l}\text { Corrected } \\
\text { total }\end{array}$ & 2,367.200 & 119 & & & & & & \\
\hline
\end{tabular}

aComputed using alpha $=0.05$.

bR-squared $=0.202$ (adjusted R-squared $=0.167$ ).

Source: Authors' calculations.

Our results also support the second hypothesis $\left(\mathrm{H}_{1}\right)$ proposing that there are significant differences in the means of student performance with respect to gender. Table 3 indicates a significant difference between the performance of men and women students $(F=9.178, \mathrm{p}=0.003)$. As Table 2 shows, men tended to perform better than women, as seen from their mean scores on the test (11.2 for men and 9.01 for women).

As far as the interaction effect on the means of student performance across different levels of grade incentive and gender is concerned, our results do not support the third hypothesis $\left(\mathrm{H}_{1}\right)$. There is no statistically significant interaction between gender and grade incentives with respect to student performance, meaning that there is no significant difference in the performance (as measured by the test mean scores) of men and women students for the different levels of incentive; the six means are not significantly different.

\subsection{Results for Accounting Students}

Table 4 gives the descriptive statistics (mean performance scores) for the second experiment. Levene's test statistic is insignificant, satisfying the basic assumption that the variance of errors for performance are the same across all groups. We can thus apply the ANOVA technique, the results of which are given in Table 5. 
Table 4: Mean performance scores for accounting students

\begin{tabular}{llccc}
\hline Incentive & \multicolumn{1}{c}{ Gender } & Mean & SD & N \\
\hline None & Male & 10.7273 & 5.95364 & 22 \\
& Female & 10.4167 & 4.39285 & 24 \\
& Total & 10.5652 & 5.14091 & 46 \\
$5 \%$ & Male & 11.9286 & 4.68162 & 14 \\
& Female & 12.4375 & 5.53737 & 16 \\
& Total & 12.2000 & 5.07462 & 30 \\
$10 \%$ & Male & 16.0333 & 5.46767 & 30 \\
& Female & 12.4286 & 7.13142 & 21 \\
\multirow{3}{*}{ Total } & Total & 14.5490 & 6.39473 & 51 \\
& Male & 13.3939 & 5.93783 & 66 \\
& Female & 11.6393 & 5.74466 & 61 \\
& Total & 12.5512 & 5.88880 & 127 \\
\hline
\end{tabular}

Source: Authors' calculations.

The results of the two-way ANOVA (Table 5) show that, for fourthyear accounting students, grade incentives affect their performance significantly $(\mathrm{F}=5.079, \mathrm{p}=0.008)$ at a confidence interval of 90 percent. Thus, there are differences in the performance of students who were given a grade incentive and those who were not. This supports our first hypothesis proposing that grade incentives affect student performance.

Post hoc tests run using Scheffe's test reconfirm these results. Students who were given a 10 percent grade incentive performed significantly better than those given a 5 percent grade incentive or no incentive at all. Table 4 indicates a mean score of 10.56 for no incentive, 12.2 for a 5 percent incentive, and 14.5 for a 10 percent incentive. 
Table 5: Two-way ANOVA results for accounting students

\begin{tabular}{|c|c|c|c|c|c|c|c|c|}
\hline \multicolumn{9}{|c|}{ Dependent variable: performance } \\
\hline Source & $\begin{array}{c}\text { Type III } \\
\text { sum of sq. }\end{array}$ & DF & Mean sq. & F & Sig. & $\begin{array}{l}\text { Partial } \\
\text { eta sq. }\end{array}$ & $\begin{array}{l}\text { Noncentr. } \\
\text { parameter }\end{array}$ & $\begin{array}{c}\text { Observed } \\
\text { power }^{\mathrm{a}}\end{array}$ \\
\hline $\begin{array}{l}\text { Corrected } \\
\text { model }\end{array}$ & $552.245^{\mathrm{b}}$ & 5 & 110.449 & 3.501 & 0.005 & 0.126 & 17.506 & 0.905 \\
\hline Intercept & $18,118.560$ & 1 & $18,118.560$ & 574.338 & 0.000 & 0.826 & 574.338 & 1.000 \\
\hline Incentive & 320.481 & 2 & 160.240 & 5.079 & 0.008 & 0.077 & 10.159 & 0.812 \\
\hline Gender & 38.423 & 1 & 38.423 & 1.218 & 0.272 & 0.010 & 1.218 & 0.195 \\
\hline $\begin{array}{l}\text { Incentive * } \\
\text { gender }\end{array}$ & 100.871 & 2 & 50.435 & 1.599 & 0.206 & 0.026 & 3.197 & 0.333 \\
\hline Error & $3,817.173$ & 121 & 31.547 & & & & & \\
\hline Total & $24,376.000$ & 127 & & & & & & \\
\hline $\begin{array}{l}\text { Corrected } \\
\text { total }\end{array}$ & $4,369.417$ & 126 & & & & & & \\
\hline
\end{tabular}

aComputed using alpha $=0.05$.

bR-squared $=0.126$ (adjusted R-squared $=0.090$ ).

Source: Authors' calculations.

Our results do not, however, support the second hypothesis (that gender affects performance) because there is no significant difference between the performance of men and women $(\mathrm{F}=1.218, \mathrm{p}=0.272)$. Both genders performed equally well on the test. The third hypothesis (that the interaction of gender and grade incentives affects student performance) is also unsupported by the results. Gender appears not to play a role as neither men nor women's performance was significantly different at different incentive levels $(\mathrm{F}=1.599, \mathrm{p}=0.206)$.

\section{Conclusion and Implications}

This experimental study on the effects of grade incentives and gender on performance yields some interesting results. Grade incentives appear to have a significant impact on performance for both mathematics and accounting students, whether first-year or fourth-year. Increasing levels of grade incentive are found to motivate students who want to improve their course performance.

Gender, on the other hand, is found to have a significant impact on performance among first-year mathematics students, but not fourthyear accounting students. Men appear to have performed better than women on the mathematics test, contradicting the general perception that women perform better. One reason for this could be that the first-year students sampled were from both coeducational and segregated 
backgrounds, accounting for a potential gender bias in their previous education. On the other hand, such bias would likely have been eliminated among the fourth-year students as a result of having already spent three years together at university.

We can also conclude that, although grade incentives affect performance, they do not affect the performance of men or women differently in either the mathematics or accounting courses.

Our research findings imply that course instructors at the university level could use the grading system as an effective tool to improve students' performance and that such incentives are likely to work equally well for both men and women students. 


\section{References}

Aloysius, O.I. (2013). Perception of empowerment among international students at the University Putra Malaysia. International Journal of Business and Management, 8(23), 93-101.

Artés, J., \& Rahona, M. (2013).Experimental evidence on the effect of grading incentives on student learning in Spain. Journal of Economic Education, 44(1), 32-46.

Arthur, N., \& Everaert, P. (2012). Gender and performance in accounting examinations: Exploring the impact of examination format. Accounting Education, 21(5), 471-487.

Borg,M. O., \& Stranahan, H.(2002). The effect of gender and race on student performance in principles of economics: The importance of personality type. Applied Economics, 34, 589-598.

Buckless, F. A., Lipe, M.G., \& Ravenscroft, S. P. (1991).Do gender effects on accounting course performance persist after controlling for general academic aptitude? Issues in Accounting Education, 6(2), 248-261.

Carpenter, C.C., \& Strawser, R. H. (1971).Initial experience with satisfactory-unsatisfactory grading in accounting courses. The Accounting Review, 46(1), 160-162.

Chung, K.H. (1968). Developing a comprehensive model of motivation and performance. Academy of Management Journal, 11(1), 63-73.

Dobrow, S. R., Smith, W. K., \& Posner, M. A. (2011). Managing the grading paradox: Leveraging the power of choice in the classroom. Academy of Management Learning and Education, 10(2), 261-276.

Doney, L. D., \& Neumann, R. C. (1965). Teaching approaches to elementary accounting. The Accounting Review, 40(3), 653-655.

Grant, D., \& Green, W. B. (2013).Grades as incentives. Empirical Economics, 44(3), 1563-1592. 
Griffin, R., MacKewn, A., Moser, E., \& Van Vuren, K. W. (2013). Learning skills and motivation: Correlates to superior academic performance. Business Education and Accreditation, 5(1), 53-65.

Harbeson, R. W. (1943). The case for an introductory course in economic theory. American Economic Review, 33(1), 121-125.

Hatcher, M., Henson, J., \& LaRosa, P. (2013).Determinants of success in an online management information systems course: The significance of grade point average as a performance predictor. International Journal of Business Strategy, 13(4), 129-132.

Huh, S., Jin, J., Lee, K. J., \& Yoo, S. (2009). Differential effects of student characteristics on performance: Online vis-à-vis offline accounting courses. Academy of Educational Leadership Journal, 13(2), 83-91.

Joseph, M.L. (1965). Role-playing in teaching economics. American Economic Review, 55(1/2), 556-565.

King, G. H., \& Mo, S. (2013).The application of Web-based learning in a managerial accounting course. Academy of Educational Leadership Journal, 17(4), 53-62.

MacDermott, R.J. (2013). The impact of assessment policy on learning: Replacement exams or grade dropping. Journal of Economic Education, 44(4), 364-371.

Maksy, M.M. (2012a). Major factors associated with the performance of students taking undergraduate accounting courses at the upper level. International Journal of Business, Accounting, and Finance, 6(2), 159-177.

Maksy, M.M. (2012b). Motivation and distraction factors associated with student performance in intermediate accounting: An empirical investigation. Journal of Accounting and Finance, 12(3), 188-208.

Marks, G. N. (2008).Gender differences in the effects of socioeconomic background: Recent cross-national evidence. International Sociology, 23(6), 845-863.

Matei,M. C., \& Abrudan, M.-A. (2011).Intrinsic and extrinsic motivation: An investigation of performance correlation on students. Annals of the University of Oradea, Economic Sciences, 20(1), 671-677. 
Picou, A. (2011). Does gender, GPA or age influence test performance in the introductory finance class? A study using linked questions. Review of Business Research, 11(4), 118-126.

Richardson, M., Abraham, C., \& Bond, R. (2012).Psychological correlates of university students' academic performance: A systematic review and meta-analysis. Psychological Bulletin, 138(2), 253-387.

Russo, C.J., \& Kaynama, S. (2012).The impact of personality type and gender on students' performance in a business capstone course. Academy of Educational Leadership Journal, 16(1), 49-67.

Tan, L. M., \& Laswad, F. (2008).Impact of prior content and metacognitive knowledge on students' performance in an introductory accounting course. Pacific Accounting Review, 20(1), 63-74. 